\title{
The role of dynamics in total ozone deviations from their long-term mean over the Northern Hemisphere
}

\author{
K. Petzoldt \\ Institut für Meteorologie der Freien Universität Berlin, \\ Carl-Heinrich-Becker Weg 6-10, D-12165 Berlin, Germany \\ Received: 2 March 1998 / Revised: 17 July 1998 / Accepted: 18 August 1998
}

\begin{abstract}
Total ozone anomalies (deviation from the long-term mean) are created by anomalous circulation patterns. The dynamically produced ozone anomalies can be estimated from known circulation parameters in the layer between the tropopause and the middle stratosphere by means of statistics. Satellite observations of ozone anomalies can be compared with those expected from dynamics. Residual negative anomalies may be due to chemical ozone destruction. The statistics are derived from a 14 year data set of TOMS (Total Ozone Mapping Spectrometer January 1979-Dec. 1992) and corresponding $300 \mathrm{hPa}$ geopotential (for the tropopause height) together with $30 \mathrm{hPa}$ temperature (for stratospheric waves) at $60^{\circ} \mathrm{N}$. The correlation coefficient for the linear multiple regression between total ozone (dependent variable) and the dynamical parameters (independent variables) is 0.88 for the zonal deviations in the winter of the Northern Hemisphere. Zonal means are also significantly dependent on circulation parameters, besides showing the known negative trend function of total ozone observed by TOMS. The significant linear trend for $60^{\circ} \mathrm{N}$ is $\sim 3 \mathrm{DU} /$ year in the winter months taking into account the dependence on the dynamics between the tropopause region and the mid-stratosphere. The highest correlation coefficient for the monthly mean total ozone anomalies is reached in November with 0.94 .
\end{abstract}

Key words. Atmospheric composition and structure (middle atmosphere - composition and chemistry) . Meteorology and atmospheric dynamics (middle atmosphere dynamics).

\section{Introduction}

After discovering how the ozone hole over Antarctica could form by heterogeneous reactions on polar stratospheric clouds (PSCs) (activating the chlorine from anthropogenic halogenated hydrocarbons) the problem arose whether an ozone hole could form over the Northern Hemisphere as well. PSCs and reactive chlorine chemicals had also been observed over the Arctic; however, there are two important factors which are different for the winter vortices in the two hemispheres. Firstly, the arctic stratosphere is warmer and thus less capable of supporting the formation of ice-coated aerosols (containing nitric acid) as often as in Antarctica, where they denitrify the vortex by falling out to lower levels. In the arctic winter vortex instead, a reservoir of inactive chlorine nitrate can be built up by the nitric acid, slowing down the further ozone destruction by chlorine (Rex, 1997). Secondly, the winter vortex over the Northern Hemisphere is disturbed by large breaking planetary waves destroying the vortex earlier in spring when the main ozone depletion takes place over Antarctica.

Nevertheless, over recent years many ozone stations in the Northern Hemisphere have reported the lowest ozone columns ever measured at their sites (Entzian et al., 1992). A negative ozone trend was also seen by satellites at middle and high latitudes (Stolarski et al., 1991), and by Dobson stations (Harris et al., 1997). Several campaigns were established to measure the ozone depletion; in the vortex of the Northern Hemisphere, values of $31-52 \%$ ozone destruction were estimated up to the winter of $1995 / 96$ at the $475 \mathrm{~K}$ potential temperature surface (Rex et al., 1996). Observed total ozone at five SAOZ stations reveals 34\% ozone destruction in 1995, when compared with simulated total ozone at the stations by a simple transport model (Goutail et al., 1997). The recent winter of 1996/ 97, with very low ozone columns at the $\mathrm{N}$ Pole, in March (Fig. 1) resembles the beginning of the ozone hole in Antarctica because the undisturbed vortex remained unusually long over the North Pole region. Total ozone amounts measured by the SBUV/2 (Planet et al., 1994) in March were 33\% lower than the 8-y (1979-86) monthly mean of March (Miller 1997).

There is no doubt about ozone destruction over the Northern Hemisphere; however, the interpretation of 


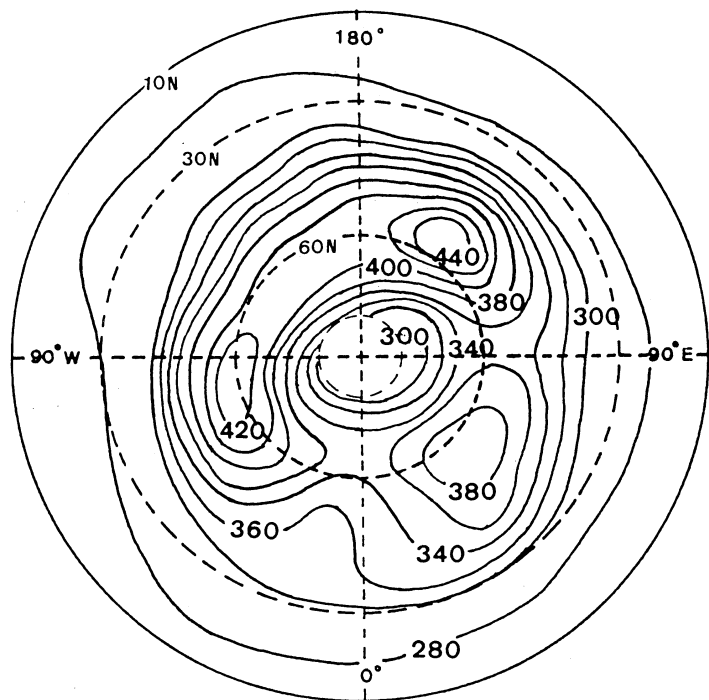

Fig. 1. Total ozone (DU) March 1997 from NOAA-9 SBUV/2. (No data in the polar region north of the dashed circle) from Miller (1997, http:/nic.fb4.noaa.gov)

zonal mean trends or monthly mean maps of total ozone must take into account the corresponding meteorological situation. It has been known for a long time, that meteorological variables are well correlated with the total ozone amount. Therefore it must be estimated how far unusual dynamical conditions are responsible for ozone deviations from the long-term mean.

This can be done either by model calculations of ozone transport or by a statistical approach. The former is difficult because of unknown vertical ozone profiles for initialisation and the long integration time. The statistical approach can be improved by taking into account the most decisive independent variables. Dobson et al. (1929) already knew the correlation between total ozone and the tropopause height. A high (cold) tropopause above an anticyclone means low total ozone because of the redistribution of low ozone content from the troposphere and lower latitudes. Since then a lot of statistical work has given more insight into the dynamical contribution to total ozone behaviour. Reed (1960) stressed the importance of vertical motion for the total ozone, while Ohring (1970) took into account the lower stratosphere. In recent publications dynamical parameters have been used. The correlation between absolute vorticity in the lower stratosphere and the total ozone column shows that synoptic scale vorticity anomalies cause perturbations in total ozone (Vaughan and Price, 1991); however, middle stratospheric anomalies disturbed the relationship. The influence of the lower stratospheric stationary waves on the longitude dependence of total ozone was investigated by Hood and Zaff (1995).

Furthermore, it could be indicated that both total ozone trend and dynamical trends show the same longitudinal dependence (Randel and Cobb, 1994 using MSU/channel 4 with $\max$ weight between 150 and $50 \mathrm{hPa}$; Peters and Entzian, 1996 using $300 \mathrm{hPa}$ ). A multiple statistical regression model for total ozone with the height and the temperature at $100 \mathrm{hPa}$ was set up by Hood et al. (1997). They could show that the negative TOMS trend for February would increase with latitude after subtracting the estimated dynamical trends (instead of showing largest negative trends at midlatitudes shown by Stolarski et al., 1991).

Here an attempt is made to improve the correlation by a multiple correlation for the anomalies of the ozone column with predictors from the tropopause height and the temperature in the middle stratosphere. For a time scale up to a month the dynamical anomalies extending into the region of maximum ozone seems to play a dominant role especially in winter.

In the first section local minima of total ozone $<225$ DU from the 14 y series (1979-1992) of TOMS satellite data are described. All cases show the same conditions in the dynamical situation from which the independent variables for the regression can be found. In the second section the regression equation is derived. The correlation coefficients and the derived values are presented for different seasons. The discussion of the results in the last section points towards the important fact, that total ozone anomaly maps for the arctic winter can be interpreted with respect to ozone destruction only after taking into account the dynamic anomalies. In particular, the fact that the total ozone column can be depleted in the same cold region by dynamics and chemical ozone destruction (upwelling by dynamics and activated chlorine by heterogenous processes on PSCs) makes it necessary to separate both effects carefully.

\section{Local minima of total ozone and meteorological conditions 1979-1992}

In a recent study Petzoldt et al. (1994) have shown that unusually large ozone anomalies in the monthly total ozone means (as in January 1992 and January 1987) were associated with large anomalies in the monthly means of the $300 \mathrm{hPa}$ height and the temperature at $30 \mathrm{hPa}$. The meteorological anomalies were caused by an unusually strong tropospheric anticyclone beneath a very cold region of the winter vortex during January.

These conditions cannot only be seen in monthly means as quasi-stationary wave perturbations, but also as transient events. Such a transient event overpassing Norway in February 1990 was described by Rabbe and Larsen (1992) as an ozone minihole. At first an ozone minihole was observed at the edge of the Antarctic polar vortex in a cold region with a bulk of isentropic levels in the upper troposphere (McKenna et al., 1989).

It is known that the large-scale waves in the stratosphere are responsible for the large-scale distribution of the total ozone (Wirth, 1993). For example, the effect of the steady pattern of wave number one in the January long-term mean at $30 \mathrm{hPa}$ can be seen in the adiabatically changed temperature as well as in the total ozone. A sinking motion causes high temperature and high ozone over the Aleutian region, whereas cold air with low ozone columns (caused by rising motion) are found over Northern Europe (Fig. 2a, b). Anomalous 
stratospheric wave amplitudes and additional effects from the troposphere produce an anomalous ozone distribution with unusually low/high values if the processes work in the same direction from the tropopause up to the middle stratosphere.

Here we investigate whether the dynamical situation described (positive anomaly of upper tropospheric levels combined with negative anomaly of the stratospheric temperature) also provides a necessary condition for all local ozone minima by scanning the daily TOMS data (1979-1992) north of $55^{\circ} \mathrm{N}$ for values below $225 \mathrm{DU}$ in January and February. This low ozone column means a large deviation from the long-term mean (anomaly), even over Europe where the ozone minimum at these latitudes is situated (see Fig. 2).
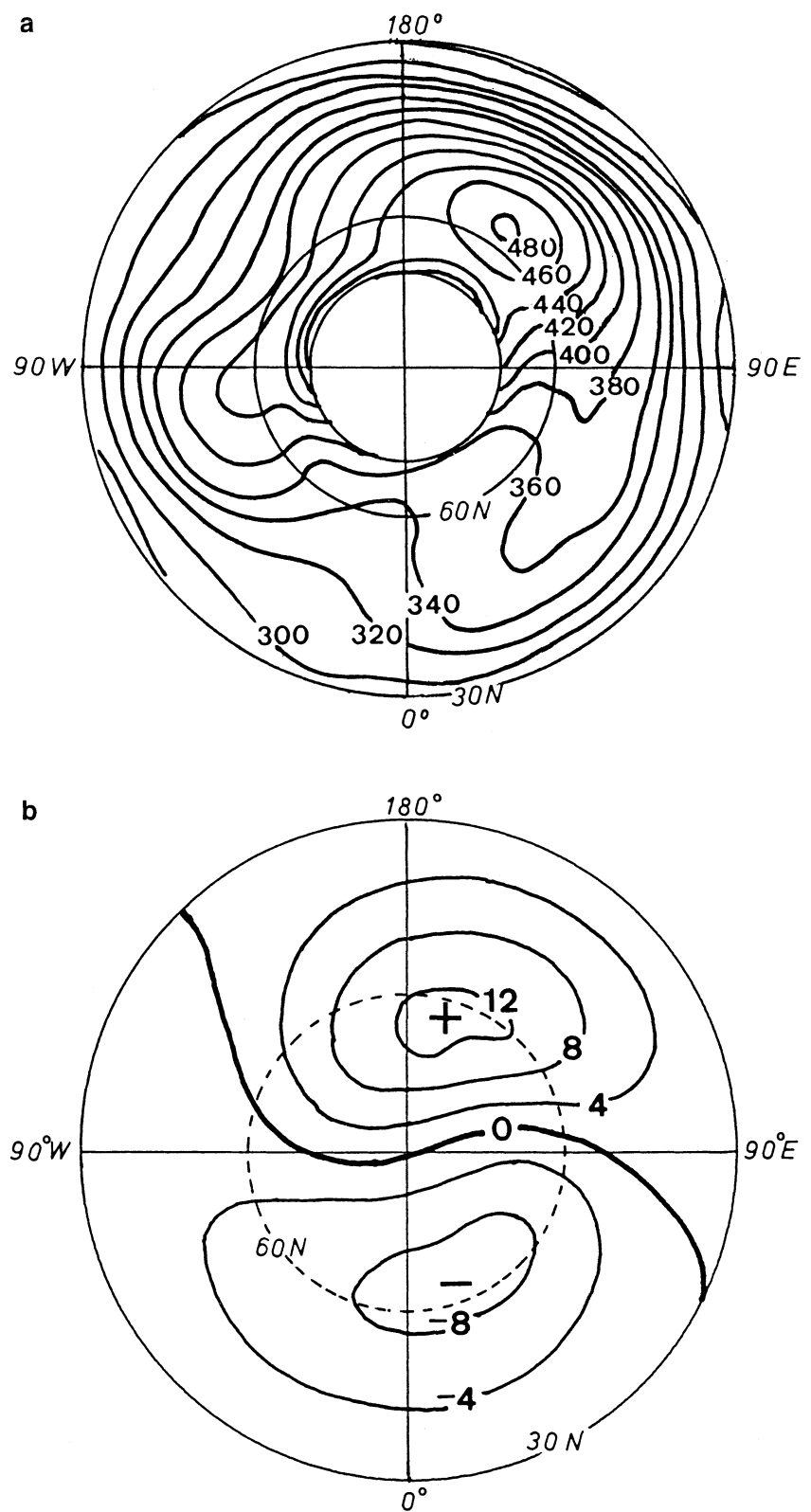

Fig. 2. a 10-y monthly mean of total ozone (DU) for January (TOMS); b 28-y monthly mean of deviations from zonal mean of 30hPa temperature for January (Pawson et al., 1994)
All 11 cases found in January and February from the period 1979-1992, when the TOMS experiment measured total ozone below $225 \mathrm{DU}$, demonstrate the same features as shown in Table 1. A tropospheric anticyclone associated with a high $200 \mathrm{hPa}$ level and low temperatures at the tropopause beneath a cold part of the stratospheric winter vortex. Whereas tropospheric anticyclones with a high cold tropopause $\left(<-70{ }^{\circ} \mathrm{C}\right)$ are often seen, stratospheric temperatures below $-83^{\circ} \mathrm{C}$ at $50^{\circ} \mathrm{N}-70^{\circ} \mathrm{N}$ are observed only during strong planetary wave activity. As seen from Table 1, all cases were associated with a strong warming in the upper stratosphere which shifted the vortex towards the European sector, connected with amplification of wave amplitudes. It can be assumed that the enhanced vertical motion during a stratospheric warming redistributes the ozone. Circulating around the vortex, the air will be lifted in the European sector and pushed downward over Siberia. In the sinking branch where the air is adiabatically warmed the ozone will increase, whereas the ozone column will decrease moving upwards along the sloping isentropic levels due to the invariant ozone mixing ratios. Of course, horizontal advection (forced by divergence due to mass continuity) has also to be taken into account, when there is a meridional ozone gradient. However, it could be shown by a linear, steady state model (Wirth, 1993) that the ozone column is well correlated with the extrema in the temperature field of the waves.

In Fig. 3 four cases for January are shown. They display transient features, when short periods occurred with total ozone values below 225 DU. They were mainly caused by propagating low-ozone centres in which the columns reached a minimum only during a few days. The hatched areas in the figures where TOMS measured less than $225 \mathrm{DU}$ are always on the northern side of the tropospheric anticyclone, just below the edge of the stratospheric vortex. Not shown in Fig. 3 is the case 2 January 1985 in Table 1, when, after a major warming, the split stratospheric vortex moved, still with very low temperatures, towards the Pacific coast of Canada.

The February cases of Table 1 show the same features (Petzoldt et al., 1994). The case in 1984 was first mentioned as an extremely low ozone column by Krueger (1989). The low ozone values during 1989 were described in the results for the AASE campaign (Airborne Arctic Stratospheric Expedition) and could be simulated in a 3-D model (Rood et al., 1991). The ozone minihole in 1990 was discussed in connection with the vertical velocity at $100 \mathrm{hPa}$ (Rabbe and Larsen, 1992). The 1992 February case was simulated (Engelen, 1997) by means of realistic wave amplitudes; the assumption was confirmed that the maximum of the ozone perturbation at $60^{\circ} \mathrm{N}$ was mainly caused by vertical motion up to the middle stratosphere.

So far, only the dynamical reasons for low ozone columns have been described here. Unfortunately, ozone depletion by chemical reactions will start in exactly the same region (low temperatures) where ozone decrease is caused by the dynamics. The low strato- 


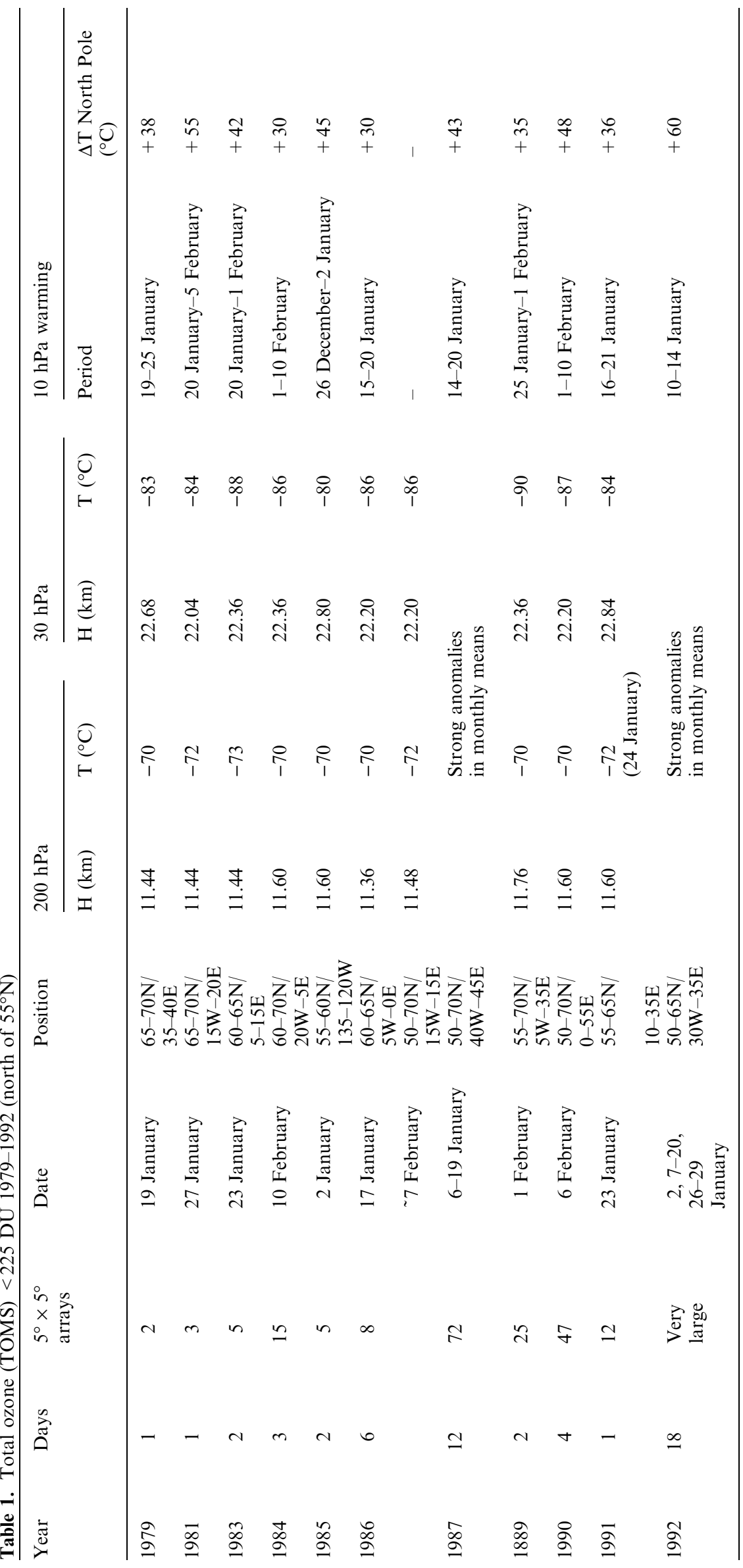




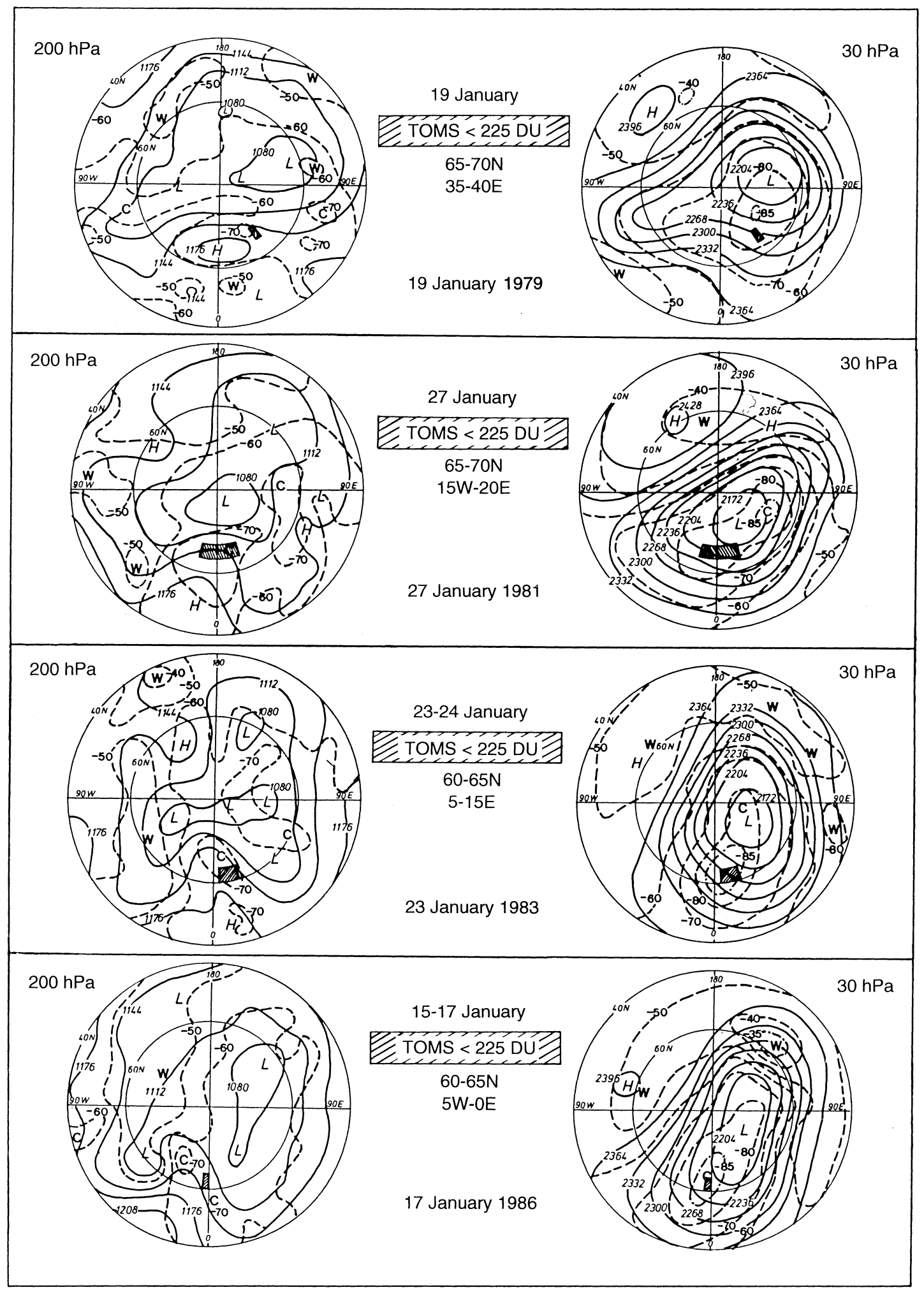

Fig. 3. Height (gpdam) (solid line) and temperature $\left({ }^{\circ} \mathrm{C}\right)$ (dashed line) at $200 \mathrm{hPa}$ (left side) and at $30 \mathrm{hPa}$ (right side) for 4 January cases when total ozone $<225$ DU (hatched areas)

spheric temperature permit the existence of PSCs, which activate the chlorine of the anthropogenic halogenated hydrocarbons by heterogeneous chemistry. For this reason, it is very difficult to decide by total ozone mapping to what extent a minimum is caused by atmospheric dynamics or by chemical ozone depletion.

From the cases discussed already it is obvious that transient and standing waves are responsible for ozone 
redistribution. Intense change will be achieved when the waves in the stratosphere are in phase. So the transient events produced lowest columns crossing the minimum of the standing wave over Northern Europe. The isentropes slope upwards and, in the uprising air, lower mixing ratios are lifted towards greater heights. When this lifting gets support from the tropopause region above an anticyclone, the ozone column can get extremely low. The negative deviation from the longterm mean will be large, and can be enlarged further by chemical ozone depletion. The effects of the dynamics have to be removed from the observed anomalies to obtain that part due to the ozone depletion. There are several approaches to solve this problem. An analytical solution of the transport equation of waves shown for the Southern Hemisphere (Schoeberl and Krueger, 1983) cannot easily be applied to the fast changing, sloping waves of the Northern Hemisphere. Three-D models are used to simulate the transported ozone for several cases in the Northern Hemisphere (Rood et al., 1991, Orsolini et al., 1994). A problem with respect to the interpretation of monthly mean anomalies is the long integration time and the initialisation with unknown disturbed ozone fields. However, a linear model could clearly show the longitudinal effect of the waves on the total ozone trend (Peters et al., 1996).

The correlation between total ozone and dynamical parameters is described in the introduction. Strong correlations can be used to construct dynamically caused total ozone distribution by statistical regression of these parameters. In the following section a multiple linear regression model is tested with two independent variables for the troposphere and the stratosphere shown to be determinative for ozone redistribution in winter.

\section{Statistical regression of the monthly mean anomaly for total ozone in the period 1979-1992}

The dependence of the anomalies of total ozone on anomalous dynamics of the troposphere and the stratosphere shown suggests the calculation of a statistical regression between the ozone anomaly and relevant parameters. To distinguish between anomalous ozone redistribution by anomalous dynamics and possible ozone destruction, the anomalies should be separated into a zonal mean anomaly and the deviations from it along a latitudinal circle. A strong correlation between ozone and dynamical parameters could be expected in these zonal deviations of the anomalies due to the redistribution by the zonal waves. On the other hand, any ozone destruction should be seen in the zonal mean, independently of where it happened.

If the chemical loss always occurs in the negative zonal deviations of the waves the dynamical redistribution would be overestimated by the statistical regression of the observed total ozone anomalies; in a preceding test however, no trend was found for the regression coefficients of the zonal deviations. Therefore it is assumed that regressed values for the ozone zonal deviations (computed with the regression coefficient derived from the statistical sample) as a function of the circulation deviations may suggest where negative ozone deviations can be expected by redistribution, regardless of whether there is also any ozone destruction or not. Of course, the results should be viewed qualitatively.

The data used are monthly mean gridded data $\left(5^{\circ}\right.$ longitudinal distance) at $60^{\circ} \mathrm{N}$. This latitude was chosen because wave amplitudes are largest there and the redistribution is expected to be strong. Furthermore, strong negative ozone anomalies were observed in the latitudinal band $50^{\circ} \mathrm{N}-70^{\circ} \mathrm{N}$ over the last few years. Due to the monthly mean values mainly quasi-stationary perturbations are considered, blocking events in the troposphere and standing waves in the stratosphere.

The local anomaly (deviation of the long-term mean: $\left.x^{*}\right)$ of a variable $x$ is the sum of the anomaly of the zonal mean (hereafter called 'zonal mean anomaly': $\bar{x}^{*}$ ) and the anomaly of the deviation from the zonal mean

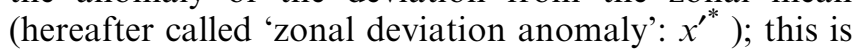
shown by separating the variable $x$ and it's long-term mean into zonal mean and the deviation from it:

$$
\begin{aligned}
x^{*} & =x-\tilde{x}=\left(\bar{x}+x^{\prime}\right)-\left(\tilde{\bar{x}}+\tilde{x}^{\prime}\right) \\
& =(\bar{x}-\tilde{\bar{x}})+\left(x^{\prime}-\tilde{x}^{\prime}\right)=\bar{x}^{*}+x^{\prime *},
\end{aligned}
$$

where $x^{*}$ is the difference of $x$ from its long-term mean $\tilde{x}$ (here called 'anomaly') $x^{\prime}$ is the deviation of $x$ from its zonal mean $\bar{x}$.

For each month 'long-term' means of the TOMS period (1979-92) were computed at all gridpoints. The difference of a single year monthly mean to this longterm mean is the gridpoint anomaly. Zonal means of those gridpoint anomalies were used to obtain the deviation from it at the gridpoint, the zonal deviation anomaly. The statistical regression was performed for each month separately for the zonal deviation anomalies and the zonal mean anomalies.

\subsection{Correlation for the zonal deviation anomalies}

Circulation disturbances change the ozone distribution by their vertical and horizontal advection. As long as the isentropic levels and the levels of constant mixing ratio do not intersect with a large angle, zonal deviations of ozone should show a good correlation with the zonal deviation of the temperature caused by the vertical motions in the wave disturbances (Wirth, 1993).

The ozone redistribution caused by synoptic scale anomalies from the tropopause through the lower stratosphere can be represented by the $300 \mathrm{hPa}$ height anomalies. The physical link is the association of a tropospheric anticyclone/cyclone with adiabatic cooling/ warming in the tropopause region.

The temperature anomalies in the middle stratosphere can be represented by the $30 \mathrm{hPa}$ temperature field which outlines the rising/sinking branches of the planetary wave disturbances.

If in both regions, from the upper troposphere to the middle stratosphere, the wave disturbances work in the 
same/opposite sense to change the ozone column, the anomalies will increase/decrease. The example shown in the former section supports this suggestion, and therefore the following linear multiple regression model is applied,

$\mathrm{TOZ}^{\prime *}=a+b 300 \mathrm{H}^{\prime *}+c 30 \mathrm{~T}^{\prime *}$

with the definition from Eq. (1), and where TOZ: total ozone; $300 \mathrm{H}$ : height of $300 \mathrm{hPa} ; 30 \mathrm{~T}$ : temperature at $30 \mathrm{hPa}$, and $a, b$, and $c$ : are regression coefficients derived from the data set.

As expected, the correlation coefficient for the multiple regression is high for each month. For the whole sample of 12096 pairs of zonal deviation anomalies (72 gridpoints in 12 months of 14 years) a multiple correlation coefficient of 0.85 is found. In Fig. 4 the correlation coefficients for the single correlations can be compared with those for the multiple correlation. It can be seen that the correlation between the ozone anomaly and the $300 \mathrm{hPa}$ anomaly (for the tropopause effect) is higher in summer when the stratospheric effect is small. In winter the correlation between the ozone anomalies and the effect of the middle stratosphere is strongest. For each month the multiple correlation is stronger than the single ones. The highest correlation coefficient of 0.93 is reached in October.

As supposed, the strong ozone anomalies appeared not only in the European sector, where the extremely low ozone columns caused public concern. In Table 2 the largest amounts of zonal deviation anomalies of ozone for the 14 January cases are shown. More than -50 DU can be seen for $120^{\circ} \mathrm{W} ; 60^{\circ} \mathrm{N}$ (1985) and $155^{\circ} \mathrm{E} ; 60^{\circ} \mathrm{N}$ (1991). Like the two European cases with more than 50 DU negative anomaly $(1987,1992)$ they are associated with strong tropospheric anticyclones beneath an extremely cold stratosphere.

\subsection{Correlation for the zonal mean anomalies}

The zonal mean anomalies $\bar{x}^{*}$ can display other reasons for ozone changes. A continuous depletion of ozone by anthropogenically released halogenated hydrocarbons should show up as a trend function for the zonal mean anomaly of that month. Aditionally, interannual variations of the circulation in the meridional plane could cause anomalies for the ozone zonal mean in that month. The dependence of the zonal mean anomalies of total ozone on the meridional circulation (shown by zonal mean anomalies of $300 \mathrm{hPa}$ height and $30 \mathrm{hPa}$ temperature) is tested by a regression equation similar to Eq. (2). The correlation between the anomalies is very weak; however, an additional linear trend function for the zonal means of the monthly mean ozone anomaly improves the multiple correlation from 0.26 to 0.70 (all months of the 14 years together):

$\overline{\mathrm{TOZ}}^{*}=A+B t+C \overline{300 \mathrm{H}}^{*}+D \overline{30 \mathrm{~T}}^{*}$

with the definitions of Eq. (1), and where $t$ is time (1,2, $\ldots 14$ years) and $A, B, C, D$ are regression coefficients to be derived from the data set.

A negative trend is shown for all months in Table 3. The largest trend occurred in the winter months with -3.1 to $-3.2 \mathrm{DU} /$ year. This supports the suspicion of chemical ozone depletion in PSCs. The zonal mean anomalies of ozone depend also (significant at the 2 sigma level) on the $300 \mathrm{hPa}$ and $30 \mathrm{hPa}$ zonal mean anomalies in January. That means that trends in the

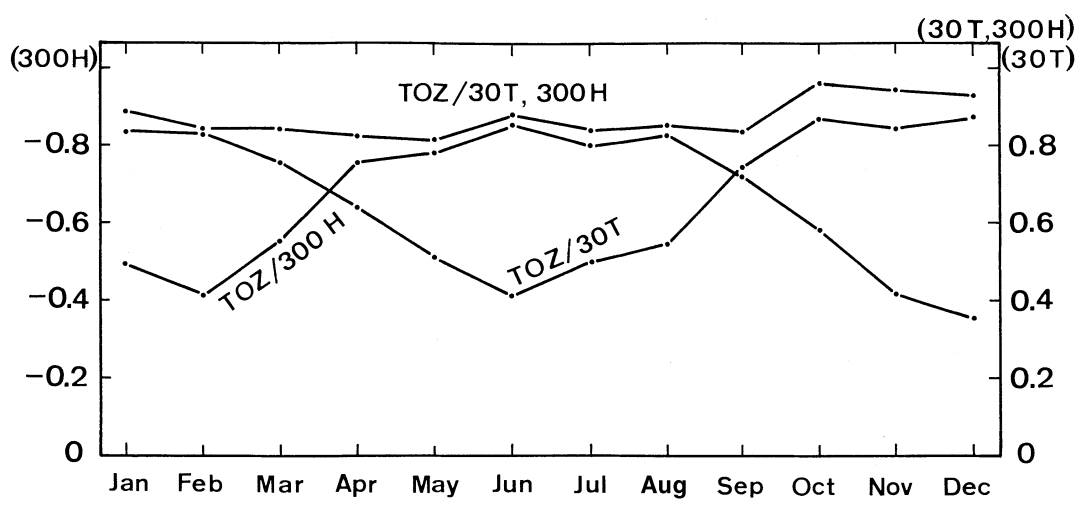

Fig. 4. Correlation coefficient for deviations from the zonal mean anomalies at $60^{\circ} \mathrm{N}$ between total ozone (TOZ), $300 \mathrm{hPa}$ height $(300 \mathrm{H})$, and $30 \mathrm{hPa}$ temperature $(30 \mathrm{~T})$

Table 2. Largest negative ozone anomaly of gridpoint deviations from zonal means at $60^{\circ} \mathrm{N}$ in Januaries $1979-1992$

\begin{tabular}{lccccccccccccccc}
\hline & 1979 & 80 & 81 & 82 & 83 & 84 & 85 & 86 & 87 & 88 & 89 & 90 & 91 & 92 \\
\hline $\mathrm{TOZ}^{\prime \mathrm{a}}$ & -49 & -41 & -25 & -27 & -12 & -25 & -63 & -31 & -56 & -31 & -34 & -39 & -51 & -57 \\
$30 \mathrm{~T}^{\mathrm{b}}$ & -3.0 & -3.3 & -4.0 & -6.5 & -3.5 & -2.3 & -12.5 & -4.6 & -10.8 & -4.2 & -5.2 & -7.4 & -6.0 & -14.5 \\
$300 \mathrm{H}^{\prime \mathrm{c}}$ & 128 & 2 & 92 & -82 & 113 & 132 & 231 & -35 & 209 & 83 & 113 & -26 & 207 & 261 \\
Position $^{\mathrm{d}}$ & $55^{\circ} \mathrm{W}$ & $75^{\circ} \mathrm{W}$ & $30^{\circ} \mathrm{W}$ & $40^{\circ} \mathrm{E}$ & $95^{\circ} \mathrm{E}$ & $155^{\circ} \mathrm{E}$ & $120^{\circ} \mathrm{W}$ & $55^{\circ} \mathrm{W}$ & $05^{\circ} \mathrm{W}$ & $130^{\circ} \mathrm{W}$ & $110^{\circ} \mathrm{E}$ & $80^{\circ} \mathrm{E}$ & $155^{\circ} \mathrm{E}$ & $10^{\circ} \mathrm{E}$ \\
\hline
\end{tabular}

${ }^{a}$ Ozone anomaly (DU)

${ }^{\mathrm{b}}$ Temperature anomaly $\left({ }^{\circ} \mathrm{C}\right)$ at $30 \mathrm{hPa}$

${ }^{\mathrm{c}}$ Height anomaly (m) at $300 \mathrm{hPa}$ ${ }^{\mathrm{d}}$ All at $60^{\circ} \mathrm{N}$ in the position of the ozone anomaly at various
longitudes 


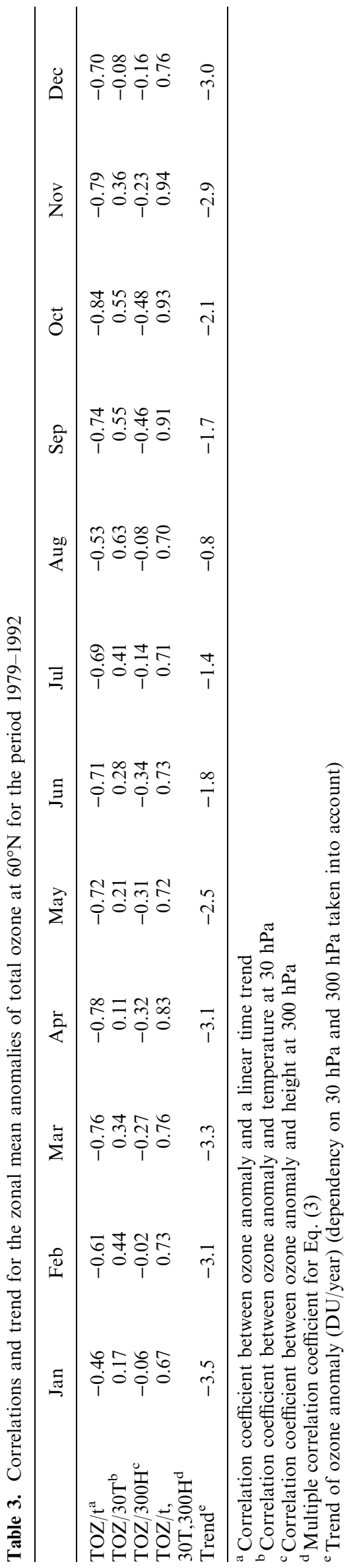

circulation parameters could be misinterpreted as ozone trends if the dynamical anomalies are neglected. With respect to cycles in the total ozone it can be tentatively assumed that they respond to the dynamics and therefore would be included in the dynamical anomalies (coherent ozone and temperature structure were found in the Quasi-Bienial-Oscillation and in the El-NinoSouthern-Oscillation by Randel and Cobb, 1994). That means that it is not necessary to remove such cycles in the ozone anomalies to get proper correlations.

The multiple correlation coefficient (also shown in Table 3 for all months) is largest in autumn with 0.94 in November and improved for all months compared with a time trend of total ozone without dynamical influence (first line of Table 3).

In Fig. 5 the observed total ozone anomalies are presented together with the computed ozone anomalies by means of Eq. (3) using the observed circulation anomalies (Geb and Naujokat, 1979-1992). Whereas the regressed ozone anomalies for November are extremely well represented by the linear regression, there seems to be more nonlinearity in January.

The largest difference between observed and regressed ozone zonal mean anomalies occurred in January 1992 when the Pinatubo volcanic aerosols disturbed the whole environment of the stratosphere. A possible effect could have been an increased potential for PSCs (Randel and $\mathrm{Wu}, 1995$ ), but also disturbed radiation fields could have affected the meridional transport. This
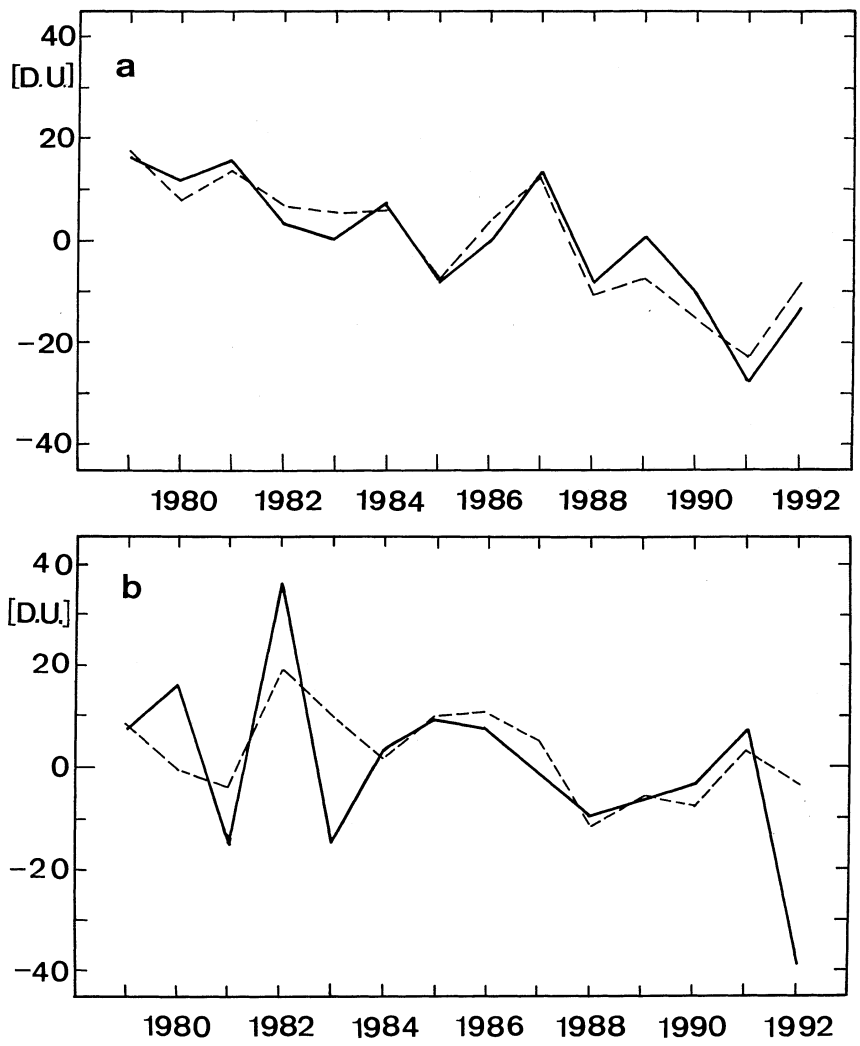

Fig. 5a, b. Anomaly (difference to long-term mean) of total ozone (DU) monthly zonal means at $60^{\circ} \mathrm{N}$ a November, b January, TOMS data (solid line) and regressed values (dashed line) (Eq. 3 in the text) 
difference increased in the winter after the eruption, November 1991: -5 DU, December 1991: -15 DU, January 1992: -20 DU, February 1992: -22 DU. A corresponding strong difference can be seen 1983 after the eruption of the volcano Chichon.

From the regression Eq. (2) for the deviations of the zonal mean and the regression Eq. (3) for the zonal mean it seems to be obvious that the extremely low anomaly in January 1992 over Northern Europe is a combined effect. Unusually strong disturbances in the stratosphere and the troposphere were associated with upward and northward transport of low ozone mixing ratios over Northern Europe contributing there to a local maximum of -100 DU total ozone anomaly. Accordingly, the regressed zonal deviation over Northern Europe reached $\sim 50 \%$ of the negative ozone anomaly, whereas the low ozone zonal mean could be tentatively explained by a linear trend of $-3.2 \mathrm{DU} /$ year and an additional effect by Pinatubo aerosols.

\section{Discussion}

Redistribution of ozone by anomalous dynamics can produce large deviations of the long-term monthly mean ('anomalies' in this article). Just in the dynamically produced region of the lowest ozone columns the temperature is also low, raising the possibility for PSCs and subsequent ozone destruction.

The separation of dynamical and chemical reasons for ozone depletion in the winter vortex is made difficult by insufficient methods for both effects. There is no doubt that there is strong ozone destruction due to heterogeneous chemical reactions during the Northern Hemisphere winter (estimated amounts are up to $52 \%$ at $475 \mathrm{~K}$ potential temperature $\sim 50 \mathrm{hPa}$, European Commission, 1997); however, monthly mean maps of the total ozone anomaly are misleading because they can be strongly influenced by anomalous dynamics.

How strong the dynamical effect on the ozone anomaly can be was shown for January 1987 and January 1992 . Up to $50 \%$ of the strong negative total ozone anomaly over Europe could be correlated (by regression coefficients of the 1979-92 sample) to the circulation anomalies of the troposphere and the stratosphere working together to reduce the ozone column by large-scale redistribution.

Another important example is the winter of 1996/ 1997, when the vortex was unusually strong until March over the North pole (Naujokat and Pawson, 1998). The negative ozone anomaly in March 97 was reported (Miller, 1997) to be more than $30 \%$ of the 8 y (1979-86) monthly mean of March (Fig. 6a). As mentioned in the introduction this negative ozone anomaly over the Arctic resembled the beginning of an ozone hole. However, taking into account the circulation anomalies of the troposphere and stratosphere in March 97 (Fig. 6a,b) it can be assumed that they contributed to the negative ozone anomaly strongly: positive anomalies at the $300 \mathrm{hPa}$ level (anticyclonic influence over the Siberian Arctic) and negative anomalies of the stratospheric
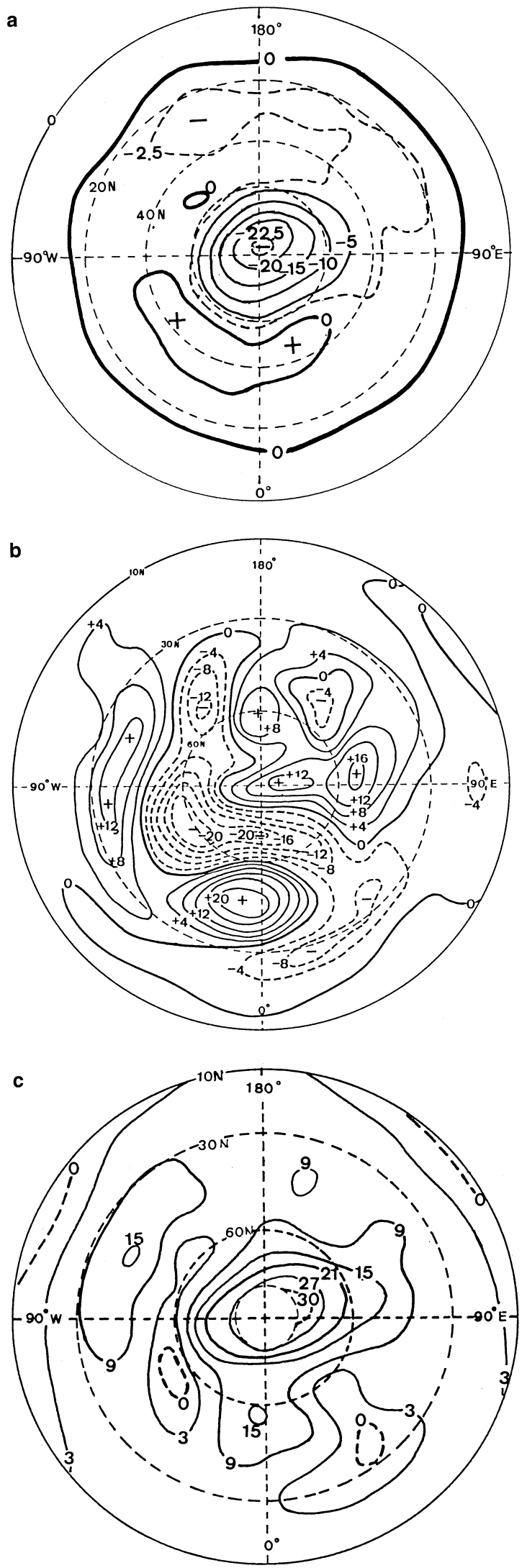

Fig. 6a-c. March 1997 deviations from long-term March means, a $30 \mathrm{hPa}$ temperature $\left({ }^{\circ} \mathrm{C}\right)$; b $300 \mathrm{hPa}$ height (gpdam); a and b from Geb and Naujokat KNH III/97 (1997); c total ozone (\% of 8-y-mean 1979-86) from Miller (1997 http://nic.fb4.noaa.gov) 
temperature at $30 \mathrm{hPa}$ north of $60^{\circ} \mathrm{N}$ (cold vortex over the polar region) are shown to reduce the ozone column by redistribution. The regression coefficients for $60^{\circ} \mathrm{N}$ derived in the former section would provide a dynamical ozone reduction of $-58 \mathrm{DU}$ at $60^{\circ} \mathrm{N} ; 90^{\circ} \mathrm{E}\left(-11^{\circ} \mathrm{C} *\right.$ $\left.4.19+140 \mathrm{~m}^{*}-0.086=-58,13\right)$. This is a large part of the reported ozone anomaly in the monthly mean map. Unfortunately no regression between ozone and dynamical anomalies is available for the $\mathrm{N}$ Pole due to the lack of satellite observations, but it seems to be clear that the polar ozone anomaly is strongly influenced by the dynamical anomalies, too. The $20^{\circ} \mathrm{C}$ negative anomaly at $30 \mathrm{hPa}$ and $100 \mathrm{~m}$ positive anomaly at $300 \mathrm{hPa}$ over polar latitudes must have provided a strong dynamical negative ozone anomaly.

For the further assessment of ozone depletion by anthropogenic halogenated hydrocarbons it seems useful to estimate the redistribution carefully. Statistical regression, model calculations and chemical ozone depletion methods should be balanced to distinguish the processes. The difference between the anomalous redistribution and the observed anomaly should confirm the depletion amounts estimated by chemical destruction methods.

The formation of an ozone hole over the arctic in spring seems to be possible only when the vortex is unusually stable and situated over the $\mathrm{N}$ Pole until March. However, the ozone depletion in the vortex normally displaced towards midlatitudes in spring is more dangerous, especially when the negative anomalies are intensified by unusual dynamics between the tropopause and the middle stratosphere.

Acknowledgements. The technical and professional assistance of the stratospheric analysis group, Free University Berlin is acknowledged. Especially appreciated is the scanning of the TOMS data (kindly provided by R. McPeters/Mark Schoeberl, Goddard Space Flight Center) by Peter Braesicke. The project was partly funded by the German Ministry for Research and Technology (BMFT/01VOZ17) and supported by the Commission of the European Communities (STEP-CT91-0139/DGXII). The $300 \mathrm{hPa}$ anomalies were kindly provided by $\mathrm{M}$. Woldt, climatology department of the meteorological institute, Free University Berlin.

Topical Editor F. Vial thanks R. J. Engelen and another referee for their help in evaluating this paper.

\section{References}

Dobson, G. M. B., D. N. Harrison, and J. Lawrence, Measurements of the amount of ozone in the Earth's atmosphere and its relation to other geophysical conditions: part III, Proc. R. Soc. London, A122, 456-486, 1929.

Engelen, R. J., The effect of planetary waves on the total ozone zonal deviations in the presence of a persistent anticyclone system, J. Geophys. Res., 101, 28 775-28 784, 1996.

Entzian, G., K. H. Grasnick, U. Feister, K. Wege, and U. Köhler, Eigenschaften von Ozon-Miniholes mittlerer Breiten, Ann. Meteor, 27, 106-112, 1992.

European Comission, Directorate-General XII, European research in the stratosphere. The contribution of EASOE and SESAME to our current understanding of the ozone layer, EUR 16986 EN, 1997.

Geb, M., and B. Naujokat, Nordhemisphärische Klimaberichte, Beilage zur Berliner Wetterkarte, Amtsblatt des Inst. f. Meteor. der FU Berlin, ISSN 0938-5312, 1979-91.
Goutail, F. J. P. Pommereau, C. Phillips, F. Lefevre, E. Kyrö, M. Rummukainen, P. Eriksen, S. B. Andersen, B. A. KaastadHoiskar, G. Braathen, V. Dorokhov, and V. U. Khattatov, Total ozone depletion in the Arctic during the winters of 1993/94 and 1994/95, J. Atmos. Chem. (in press), 1997.

Harris, N. R. P., G. Ancellet, L. Bishop, D. J. Hofmann, J. B. Kerr, R. D. McPeters, M. Prendez, W. J. Randel, J. Staehelin, B. H. Subbaraya, A. Volz-Thomas, J. Zawodny, and C. S. Zerefos, Trends in stratospheric and free tropospheric ozone, J. Geophys. Res., 102, 1571-1590, 1997.

Hood, L., and D. Zaff, Lower stratospheric stationary waves and the longitude dependence of ozone trends in winter, J. Geophys. Res., 100, 25 791-25 800, 1995.

Hood, L. L., J. P. McCormack and K. Labitzke, An investigation of dynamical contributions to midlatitude ozone trends in winter, J. Geophys. Res., 102, 13 079-13 093, 1997.

Krueger, A. J., Antarctic and arctic total ozone extreme minima. Ed. R.D. Bojkov and P. Fabian, Ozone in the Atmosphere, A. Deepak, 1989.

McCormack J. P., and L. L. Hood, Modeling the spatial distribution of total ozone in northern hemisphere winter: 1979-1991, J. Geophys. Res., 102, 13 711-13 717, 1997.

McKenna, D. S. R. L. Jones, J. Austin, E. V. Browell, M. P. McCormick, A. J. Krueger, and A. F. Tuck, Diagnostic studies of the Antarctic vortex during the Airborne Antarctic Ozone Experiment: ozone miniholes, J. Geophys. Res., 94, 11 64111669

Miller, A. J., Northern Hemisphere Winter Summary 1996/97. NOAA/NCEP available in WWW http://nic.fb4.noaa.gov; location: products/stratosphere/winter_bulletins, 1997.

Naujokat, B., and S. Pawson, The unusually cold, persistent vortex in spring 1997, BMBF Air Poll. Res Rep. 66, 50-53, 1998.

Ohring, G., and H. S. Muench, Relationship between $\mathrm{O}_{3}$ and meteorological parameters in the lower stratosphere, J. Meteorol., 17, 195-206, 1960.

Orsolini, Y., D. Cariolle, and M. Deque, A GCM study of the late January 1992 "mini-hole" event observed during EASOE, Geophys. Res. Lett, 21, 1459-1462, 1994.

Pawson, S., K. Labitzke, R. Lenschow, B. Naujokat, B. Rajewski, M. Wiesner, and R. Wohlfart, Climatology of the Northern Hemisphere stratosphere. Derived from Berlin Analyses. Part 1: monthly means, Meteorol. Abhdlg. Serie A, 7, Heft 3. Freie Universität Berlin, 1993.

Peters, D., and G. Entzian, January ozone anomaly over the North Atlantic-European region: Longitude-dependent decadal change in total ozone during 1979-92, Meteorol. Z.N.F. 5, 41-44, 1996.

Peters, D., et. al., Ozone anomalies over the North AtlanticEuropean region during January 1979-92: linear modeling of horizontal and vertical ozone transport by ultra-long waves, Contrib. Atmos. Phys., 69, 477-489, 1996.

Petzoldt, K., B. Naujakat, and K. Neugebohren, Correlation of total ozone, stratospheric temperature and tropospheric weather systems, Geophys. Res. Lett., Special EASOE Issue, 21, 12031206, 1993.

Planet, W. G., J. H. Lienesch, A. J. Miller, R. Nagatani, R. D. McPeters, E. Hilsenrath, R. P. Cebula, M. T. DeLand, C. G. Wellemeyer, and K. Horrath, Northern Hemisphere total ozone values from 1989-1993 determined with the NOAA-11 Solar Backscatter Ultraviolet (SBUV/2) instrument, Geophys. Res. Lett., 21, 205-208, 1994.

Rabbe, A., and S. H. H. Larsen, Ozone 'minihole' over Northern Scandinavia, JATP, 54, 1447-1451, 1992.

Randel W. J., and J. B. Cobb, Coherent variations of monthly mean total ozone and lower stratospheric temperature, J. Geophys. Res. 99, 5433-5447, 1994.

Randel W. J. and F. Wu, Ozone and temperature changes in the stratosphere following the eruption of Mount Pinatubo, J. Geophys. Res., 100, 16 753-16 764, 1995.

Reed, R. J., The role of vertical motions in ozone-weather relationships, J. Meteorol., 7, 263-267, 1950. 
Rex, M., Der Ozonabbau in der arktischen Stratosphäre: Ergebnisse einer neuen Meßstrategie (Match), Dissertation im Fachbereich Geowissenschaften der Freien Universität Berlin, 1997.

Rex, M., N. R. P. Harris, P. von der Gathen, R. Lehmann, G. O. Braathen, E. Reimer, A. Beck, M. Chipperfield, R. Alfier, M. Allaart, F. O'Connor, H. Dier, V. Dorokhov, H. Fast, M. Gil, E. Kyrö, Z. Litynska, I. S. Mikelsen, M. Molyneux, H. Nakane, M. Rummukainen, P. Viatte, and J. Wenger, Prolonged stratospheric ozone loss in the 1995/96 Arctic winter, Nature, in press, 1997.

Rood, R. B., A. R. Douglass, J. A. Kaye, M. A. Geller, C. Yuechen, D. J. Allen, E. M. Larson, E. R. Nash, and J. E. Nielsen, Three- dimensional simulation of wintertime ozone variability in the lower stratosphere, J. Geophys. Res., 96, 5055-5071, 1991.

Schoeberl M. R., and A. J. Krueger, Medium scale disturbances in total ozone during Southern hemisphere summer, Bull. Am. Meteorol. Soc., 64, 1358-1365, 1983.

Stolarski R. S., P. Bloomfield, and R. D. McPeters, Total ozone trends deduced from Nimbus 7 TOMS data, Geophys. Res. Lett., 18, 1015-1018, 1991.

Vaughan, G., and J. D. Price, On the relation between total ozone and meteorology, Q. J. R. Meteorol. Soc, 117, 1281-1298, 1991.

Wirth, V., Quasi-stationary planetary waves in total ozone and their correlation with lower stratospheric temperatures, J. Geophys. Res., 98, 8873-8882, 1993. 